\title{
Tumor-associated immune cell infiltrate density in penile squamous cell carcinomas
}

\author{
Luca Hladek ${ }^{1} \cdot$ Katrin Bankov ${ }^{1}$. Jens von der Grün ${ }^{2} \cdot$ Natalie Filmann $^{3} \cdot$ Melanie Demes $^{1} \cdot$ Stefan Vallo ${ }^{4,5}$. \\ Peter J. Wild ${ }^{1,6,7} \cdot$ Ria Winkelmann $^{1}$ (])
}

Received: 13 October 2021 / Revised: 3 January 2022 / Accepted: 4 January 2022 / Published online: 13 January 2022

(c) The Author(s) 2022

\begin{abstract}
Penile squamous cell carcinomas are rare tumor entities throughout Europe. Early lymphonodal spread urges for aggressive therapeutic approaches in advanced tumor stages. Therefore, understanding tumor biology and its microenvironment and correlation with known survival data is of substantial interest in order to establish treatment strategies adapted to the individual patient. Fifty-five therapy naïve squamous cell carcinomas, age range between 41 and 85 years with known clinicopathological data, were investigated with the use of tissue microarrays (TMA) regarding the tumor-associated immune cell infiltrate density (ICID). Slides were stained with antibodies against CD3, CD8 and CD20. An image analysis software was applied for evaluation. Data were correlated with clinicopathological characteristics and overall survival. There was a significant increase of ICID in squamous cell carcinomas of the penis in relation to tumor adjacent physiological tissue. Higher CD3positive ICID was significantly associated with lower tumor stage in our cohort. The ICID was not associated with overall survival. Our data sharpens the view on tumor-associated immune cell infiltrate in penile squamous cell carcinomas with an unbiased digital and automated cell count. Further investigations on the immune cell infiltrate and its prognostic and possible therapeutic impact are needed.
\end{abstract}

Keywords Penile carcinomas $\cdot$ Tumor microenvironment $\cdot$ Tissue microarray $\cdot$ Antibodies

\section{Abbreviations \\ ICID Tumor-associated immune cell infiltrate density \\ SCC Squamous cell carcinoma(s) \\ FFPE Formalin fixed paraffin embedded \\ HE Hematoxylin and eosin}

Ria Winkelmann

ria.winkelmann@kgu.de

1 Dr. Senckenberg Institute of Pathology, University Hospital Frankfurt, Goethe University, Frankfurt am Main, Germany

2 Department of Radiotherapy and Oncology, University Hospital Frankfurt, Goethe University, Frankfurt am Main, Germany

3 Institute of Biostatistics and Mathematical Modeling, Goethe University, Frankfurt am Main, Germany

4 Institute of Medical Virology, Goethe University Frankfurt, Frankfurt am Main, Germany

5 Urologie an der Zeil, Frankfurt am Main, Germany

6 Frankfurt Institute for Advanced Studies (FIAS), Frankfurt am Main, Germany

7 Wildlab, University Hospital Frankfurt MVZ GmbH, Frankfurt am Main, Germany
UCT University Cancer Center Frankfurt

ROI Region(s) of interest

TMA Tissue microarray

CIS Carcinoma in situ

HPV Human papillomavirus

OS Overall survival

\section{Introduction}

Penile neoplasias are orphan diseases in Europe which can be treated with good overall survival in case of early detection. Later stages demand for aggressive therapeutic approaches because of early lymphonodal spread [1]. Most of the penile neoplasias are squamous cell carcinomas (SCC) [2]. In the WHO classification of Tumours of the Urinary System and Male Genital Organs, there are three main categories for penile squamous carcinomas: Tumors not attributed to infections by human papillomavirus (HPV), tumors with association to HPV [3] and other rare carcinomas [2]. TNM stage, depth of invasion, lymphonodal status, perineural invasion and grading are the main prognostic factors 
known by now $[4,5]$. Apart from these factors, a focus was drawn to the tumor-associated immune cell response in recent years. Attempts on measuring this answer have been made in different tumor entities to generate information on the patients' outcome. Familiar examples are breast cancer [6], head and neck cancer [7], anal squamous cell carcinoma [8] and cervical cancer [9] to only name a few entities. For penile carcinomas, data is sparse. From a previous study, it is known that squamous cell carcinomas of the penis related to infection by HPV are associated with a different amount and composition of tumor infiltrating lymphocytes than nonHPV related squamous cell carcinomas of the penis [10]. Additionally, studies attempting to gain knowledge on the amount and prognostic impact of immune cells were conducted [11, 12]. In general, from an immunological point of view, tumors are separated into subgroups with low immune cell infiltrate, medium amount of immune cell infiltrate and high immune cell infiltrate [13].

With the advent of digital tools and artificial intelligence also into the field of pathology, an automated image analysis software for our investigations on squamous cell carcinomas of the penis was applied. The goal was to gain an unbiased view on the immune cell infiltrate of the penis in a cohort by not relying on individual pathologist's assessments. This technique is reproducible and produces automated machine generated numbers. Correlation of these data to known tumor characteristics was aimed.

In our study, we investigated the tumor-associated immune cell infiltrate density (ICID) with three antibodies: CD3 and CD8 (T-cells) and CD20 (B-cells). For malignant melanoma, for example, presence of positive staining against these CD molecules is associated with differing patient outcome $[14,15]$. Therefore, our aim was to measure the immune cells stained with the aforementioned antibodies and to generate data on its association with known clinicopathological features in a cohort of penile squamous cell carcinomas.

\section{Materials and methods}

\section{Patients}

Fifty-five therapy-naïve cases of invasive squamous cell carcinomas of the penis from the Dr. Senckenberg Institute of Pathology, Frankfurt am Main, Germany were investigated. All cases of penile squamous cell carcinomas that had sufficient tissue material and were diagnosed between October 2001 and October 2017 were selected from the biobank of the Dr. Senckenberg Institute of Pathology. From a total of 70 cases that were available, 15 were excluded in the process of case preparation and later analyses: Cases with insufficient tissue material $(n=2)$ were excluded from the beginning. Further exclusions were made for cases in which no invasive carcinoma was present $(n=6)$ and cases which were classified as metastases $(n=2)$ and thus were not primary penile carcinomas. One case of penile basal cell carcinoma and one case of penile Paget's disease, focally invasive $(n=2)$, were also excluded. Cases in which no TMA cores were available, or all available cores were defined as missing, were also excluded $(n=3)$. Tumor classification according to the current WHO classification system [16] was available for all patients, as well as infection status with human papillomavirus (HPV) gained via LCD array technique, as described before [17]. Clinicopathological characteristics are presented in Table 1.

Clinical follow-up was available for all patients. Overall survival was calculated from the date of biopsy to the date of last follow-up or death by any cause.

Formalin fixed paraffin embedded (FFPE) material resection specimens and biopsy probes were processed subsequently to diagnostic procedures. The specimens were surgical specimens. Material and pseudonymized patient data used in this study were provided by the University Cancer Center Frankfurt (UCT). Written informed consent was obtained from all patients, and the study was approved by the institutional review board of the UCT and the ethical committee at the University Hospital Frankfurt, according to the Declaration of Helsinki (project-numbers: SUG-022017, SUG-6-2018).

\section{Determination of disease representative areas}

FFPE materials were routinely kept at room temperature (RT) and chilled on a cooling plate before sectioning. Current hematoxylin eosin (HE) stained sections underwent an additional pathology review to confirm and select disease representative regions of interest (ROI) including carcinoma, corresponding carcinoma in situ (CIS) and tumor adjacent physiological tissue.

\section{Slide digitization and production of a human tissue microarray (TMA)}

HE stains were digitized using a $20 \times$ brightfield slide scanner (Pannoramic Scan II, 3D Histech, Budapest, Hungary). Annotations of defined ROI were set to a core diameter of 1 $\mathrm{mm}$. The TMA was produced using the TMA Grand Master (3DHistech, Budapest, Hungary) and matching settings of 1 $\mathrm{mm}$ core diameter. Via slide overlay function, digital annotations were matched to the donor tissue and transferred to an empty recipient paraffin matrix. In total, three TMAs were produced, each containing well-characterized areas of the tumor and tumor adjacent physiological tissue as well as CIS to address tumor heterogeneity. Three ROIs for non-tumoral adjacent areas and six ROIs of carcinoma and corresponding 
Table 1 Clinicopathological characteristics of invasive penile carcinomas $(n=55)$

\begin{tabular}{|c|c|c|c|}
\hline $\begin{array}{l}\text { Clinicopathological characteris- } \\
\text { tics of invasive penile carcinomas }\end{array}$ & Categorization & $n$ & $\%$ \\
\hline \multirow[t]{2}{*}{ Age (range $41-85$ years) } & $<65$ years & 26 & 47 \\
\hline & $\geq 65$ years & 29 & 53 \\
\hline \multirow[t]{6}{*}{ Tumor stage } & pT1a & 22 & 40 \\
\hline & pT1b & 6 & 11 \\
\hline & pT2 & 22 & 40 \\
\hline & pT3 & 2 & 4 \\
\hline & pT4 & 2 & 4 \\
\hline & pTX & 1 & 2 \\
\hline \multirow[t]{3}{*}{ Nodal status } & pNO & 12 & 22 \\
\hline & $\mathrm{pN}>0$ & 8 & 15 \\
\hline & $\mathrm{pNX}$ & 35 & 64 \\
\hline \multirow[t]{3}{*}{ Grading } & G1 & 11 & 20 \\
\hline & $\mathrm{G} 2$ & 35 & 64 \\
\hline & G3 & 9 & 16 \\
\hline \multirow[t]{2}{*}{$\mathrm{L}$} & L0 & 43 & 78 \\
\hline & L1 & 12 & 22 \\
\hline \multirow[t]{2}{*}{$\mathrm{V}$} & V0 & 50 & 91 \\
\hline & V1 & 5 & 9 \\
\hline \multirow[t]{2}{*}{ Pn } & Pn0 & 49 & 89 \\
\hline & Pn1 & 6 & 11 \\
\hline \multirow[t]{4}{*}{$\mathrm{R}$} & R0 & 45 & 82 \\
\hline & $\mathrm{R} 1$ & 3 & 5 \\
\hline & $\mathrm{R} 1$ (is) & 3 & 5 \\
\hline & $\mathrm{RX}$ & 4 & 7 \\
\hline \multirow[t]{2}{*}{ Infiltration pattern } & Infiltrative pattern & 34 & 62 \\
\hline & Pushing margin & 21 & 38 \\
\hline \multirow[t]{2}{*}{ Morphological tumor type } & Usual & 49 & 89 \\
\hline & Basaloid & 6 & 11 \\
\hline \multirow[t]{4}{*}{ HPV status (LCD array) } & Negative & 22 & 40 \\
\hline & Low risk & 2 & 4 \\
\hline & High risk & 29 & 53 \\
\hline & Unknown & 2 & 4 \\
\hline \multicolumn{4}{|l|}{ Immunohistochemistry (IHC) } \\
\hline \multirow[t]{2}{*}{ p16 IHC } & Negative & 26 & 47 \\
\hline & Positive & 29 & 53 \\
\hline
\end{tabular}

Tumor stage: Nomenclature according to current WHO classification system, Nodal stage $-\mathrm{pN} 0$ : No tumor infiltrated lymph nodes detected in pathological examination, $\mathrm{pN}>0$ : Tumor infiltrated lymph nodes detected in pathological examination, pNX: Pathological lymphonodal status unknown, L: Lymphovascular invasion-L0: No lymphovascular invasion, L1: Lymphovascular invasion, V: Vascular invasion-V0: No vascular invasion, V1: Vascular invasion, Pn: Perineural invasion-Pn0: No perineural invasion, Pn1: Perineural invasion; R: Residual tumor-R0: No residual tumor, R1: Residual tumor; R1(is): Residual carcinoma in situ, RX: Unknown status. HPV: Human papillomavirus

CIS were defined per case. In the instances that the case provided insufficient tissue material for a total number of nine cores, less ROIs were defined, and therefore less than nine cores were produced.

\section{Immunohistochemistry}

TMA sections were analyzed regarding the immune infiltrate of T-cells and B-cells by CD3, CD8 and CD20 targeting antibodies, respectively. Immunohistochemistry was performed using the DAKO FLEX-Envision Kit (Agilent, Santa Clara, CA, US) and the fully automated DAKO Omnis staining system (Agilent, Santa Clara, CA, US) according to manufacturer's instruction. DAKO CD3 primary antibody (GA503, ready to use dilution, Agilent, Santa Clara, CA, US), CD8 primary antibody (GA623, ready to use dilution, Agilent, Santa Clara, CA, US) and CD20 primary antibody (GA604, ready to use dilution, Agilent, Santa Clara, CA, US) were used for immunohistochemical epitope staining applied for $30 \mathrm{~min}$ after heat-induced epitope retrieval in pH6 at $97{ }^{\circ} \mathrm{C}$. Epitope visualization was done by DAKO EnVision ${ }^{\mathrm{TM}}$ FLEX DAB + Substrate Chromogen System (Agilent, Santa Clara, CA, US) resulting in brown-ish cytoplasmic, membranous signal. Nuclear counterstain was done using DAKO hematoxylin solution (Agilent, Santa Clara, CA, US). Slide staining was supported by Nina Becker (technical assistant at Dr. Senckenberg Institute of Pathology, University Hospital Frankfurt, Frankfurt am Main and University Cancer Center, Goethe University Frankfurt am Main). The stained TMA slides were digitized as mentioned in the previous paragraph (Pannoramic Scan II, 3D Histech, Budapest, Hungary). The TMA process and its digital evaluation are shown in a schematic representation in Fig. 1.

\section{Evaluation of the stainings}

Digitized TMA slides were analyzed using QuPath (Version 0.2.0), an open source software for image analysis [18]. Preprocessing and tissue and cell detection were conducted as suggested in the software's documentation. Optical quality control and pathology review were performed. Missing TMA cores were defined as such, if not yet automatically identified by QuPath, and artifacts were removed. Per TMA core, QuPath returned absolute numbers of positively stained cells as well as a density value that counted this number of positive cells in relation to the detected total tissue area of the TMA core, resulting in a value that indicated the tumorassociated immune cell infiltrate density (ICID) for the specific stain for each core as the number of positive cells per $\mathrm{mm}^{2}$.

Per stain, a mean density value for every patient for each tumor and tumor adjacent physiological tissue was calculated separately. TMA cores containing tissue material from CIS regions were assigned to the tumor group. Six mean density values per patient were generated for tumor and 
Fig. 1 Schematic representation of the process of building the TMA and its digital evaluation. The cores depicted on the bottom show the same core of the TMAs with different stains

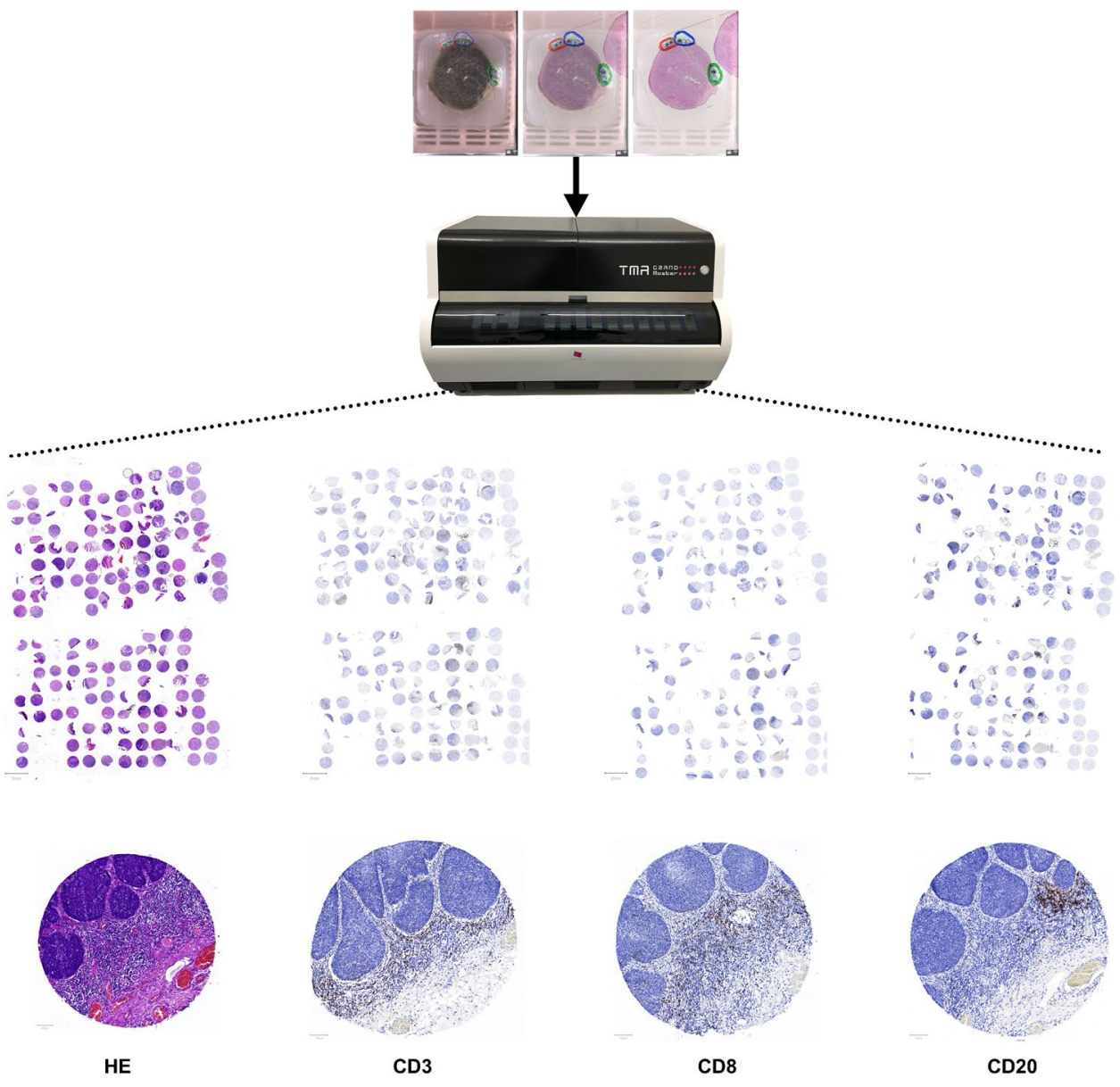

tumor adjacent physiological tissue per stain. For correlations and survival analysis, only the densities in neoplastic tissues were used. Data for intra- and peritumoral immune cells were not generated separately, as the purpose was to assess the distinction between tumor and tumor adjacent physiological tissue.

The computed density means for neoplastic tissues were used to calculate a median split that divided the samples into two groups. For the three stains separately, mean density values above the median mean density value were grouped in the high group, mean densities smaller than the median grouped in the low category.

Furthermore, ratios of the aforementioned calculated density means were generated by dividing them by themselves. The calculated density ratios were also grouped into groups with high or low ratios, according to their relation to the median as outlined before.

\section{Statistical analyses}

Statistical analyses were conducted with R Version 4.1.0 [19] in R Studio, Version 1.4.1717 [20]. Used packages include inter alia the ggplot2 v3.3.5 [21], psych v2.1.6 [22] and survival v3.2-11 [23] packages. The full reproducible code used for the analyses can be found in the Online Resource 1.

Differences between the groups shown in Fig. 2 were calculated using Kruskal-Wallis and paired exact Wilcoxon-Pratt Signed-Rank Test with the reported $p$ values corrected by Bonferroni's method. Correlations between ICID and clinicopathological characteristics were calculated using either Spearman's rank correlation for correlating interval type data with other interval type data, pointbiserial correlation for correlating interval type data with dichotomous variables or using Kendall's correlation as equivalent to the Jonckheere-Terpstra test for correlating interval type data with ordinal type data. No Bonferroni correction was applied to the correlation $p$ values due to the exploratory nature of the correlation calculations.

Overall survival was analyzed by Kaplan-Meier estimators. Patients were censored at the point of their last clinical follow-up visit. Statistical significance was considered for $p<0.05$. 


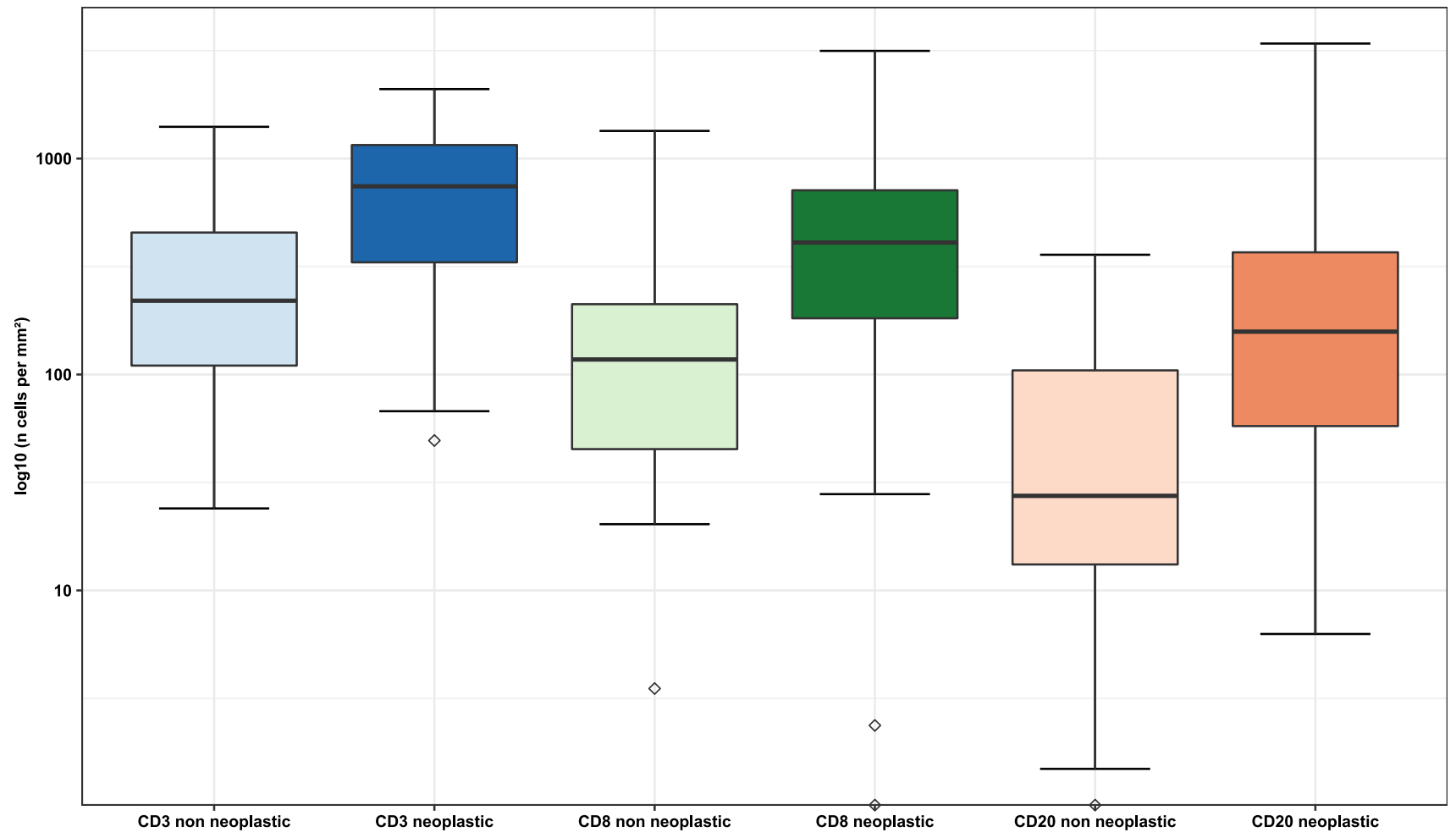

Fig. 2 Graphical representation of differences in tumor-associated immune cell infiltrate density (ICID) between normal and neoplastic tissue. Density of CD3-positive cells differs significantly between normal and neoplastic tissue $(p=0.0007)$; the same is true for CD8positive cells $(p=0.0387)$ and CD20-positive cells $(p=0.0025)$. Furthermore, there are significant differences in the densities of

\section{Results}

\section{Tumor and non-tumor tissue show different ICID}

Comparing tumor and non-tumor tissue of our cohort of invasive squamous cell carcinomas of the penis, statistically significant differences in the distribution of the ICID stained via CD3, CD8 and CD20 antibodies were detected (Fig. 3). For all three stains, non-neoplastic tissue showed lower amounts of the assessed types of immune cells than corresponding neoplastic tissue (Fig. 2). Additionally, we found that the densities of the three stained positive immune cells differed significantly in neoplastic tissue (Fig. 2).

\section{Correlation of ICID with clinicopathological characteristics}

Recorded tumor and clinicopathological characteristics were correlated with the attained ICID values separately as described above. Data are presented in Table 2. A significant correlation was found between lower tumor stage and higher density of CD3-positive ICID ( $p=0.03, r=$ $-0.31)$. No significant correlations with the ICID were
CD3, CD8 and CD20-positive cells in neoplastic tissue: The difference between CD3-positive ICID and CD8-positive ICID is significant with $p=0.0001$, the difference between CD3-positive ICID and CD20-positive ICID with $p<0.0001$ and the difference between CD8-positive ICID and CD20-positive ICID with $p=0.0061$

found for age group, lymphonodal status, tumor grading, lymphatic vessel invasion status, vascular invasion status, perineural infiltration (Pn), resection boundaries status, infiltration pattern, HPV status and p16 status. Basaloid tumor type related to a higher density of CD8-positive cells $(p=0.02, r=0.33)$ in this cohort. There were no significant correlations between the calculated density ratios and recorded tumor characteristics, as shown in Supplementary Table 1.

\section{Correlation of ICID and outcome}

There was no significant association between overall survival (OS) and ICID groups (low versus high ICID) measured by CD3, CD8 and CD20-positive cells (Fig. 4). Similarly, a significant association of the ICID ratios and their groups with OS was not shown (Supplementary Figure 1). A trend towards differing survival can be estimated. Additionally, correlations for the density ratios were calculated. Results are shown in the Supplementary Table 1. There was no significant association of the ICID ratios in relation to clinicopathological characteristics in the cohort. 
Fig. 3 Visual impression of the different immune cell infiltrate in exemplary TMA cores with low vs high immune cell infiltrate density. TMA cores were stained using immunohistochemistry antibodies as described in the text. a shows a core with low CD3-positive cell count (317.08 pos. cells per $\left.\mathrm{mm}^{2}\right), \boldsymbol{b}$ shows a core with high CD3-positive cell count (3339.45 pos. cells per $\mathrm{mm}^{2}$ ). Median CD3 cell density for all patients was 512.24 pos. cells per $\mathrm{mm}^{2}$. c shows a core with low CD8-positive cell count (188.25 pos. cells per $\mathrm{mm}^{2}$ ), $\boldsymbol{d}$ shows a core with high CD8-positive cell count (1313.28 pos. cells per $\mathrm{mm}^{2}$ ). Median CD8 cell density for all patients was 217.53 pos. cells per $\mathrm{mm}^{2}$. e shows a core with low CD20-positive cell count (34.10 pos. cells per $\left.\mathrm{mm}^{2}\right), \boldsymbol{f}$ shows a core with high CD20positive cell count (768.07 pos. cells per $\mathrm{mm}^{2}$ ). Median CD2O cell density for all patients was 80.78 pos. cells per $\mathrm{mm}^{2}$. Density values are not to be interpreted as absolute numbers but to be looked at in relation to one another as they are highly specific to methods and sample material. Consequently, absolute numbers displayed here might not be directly comparable to other data

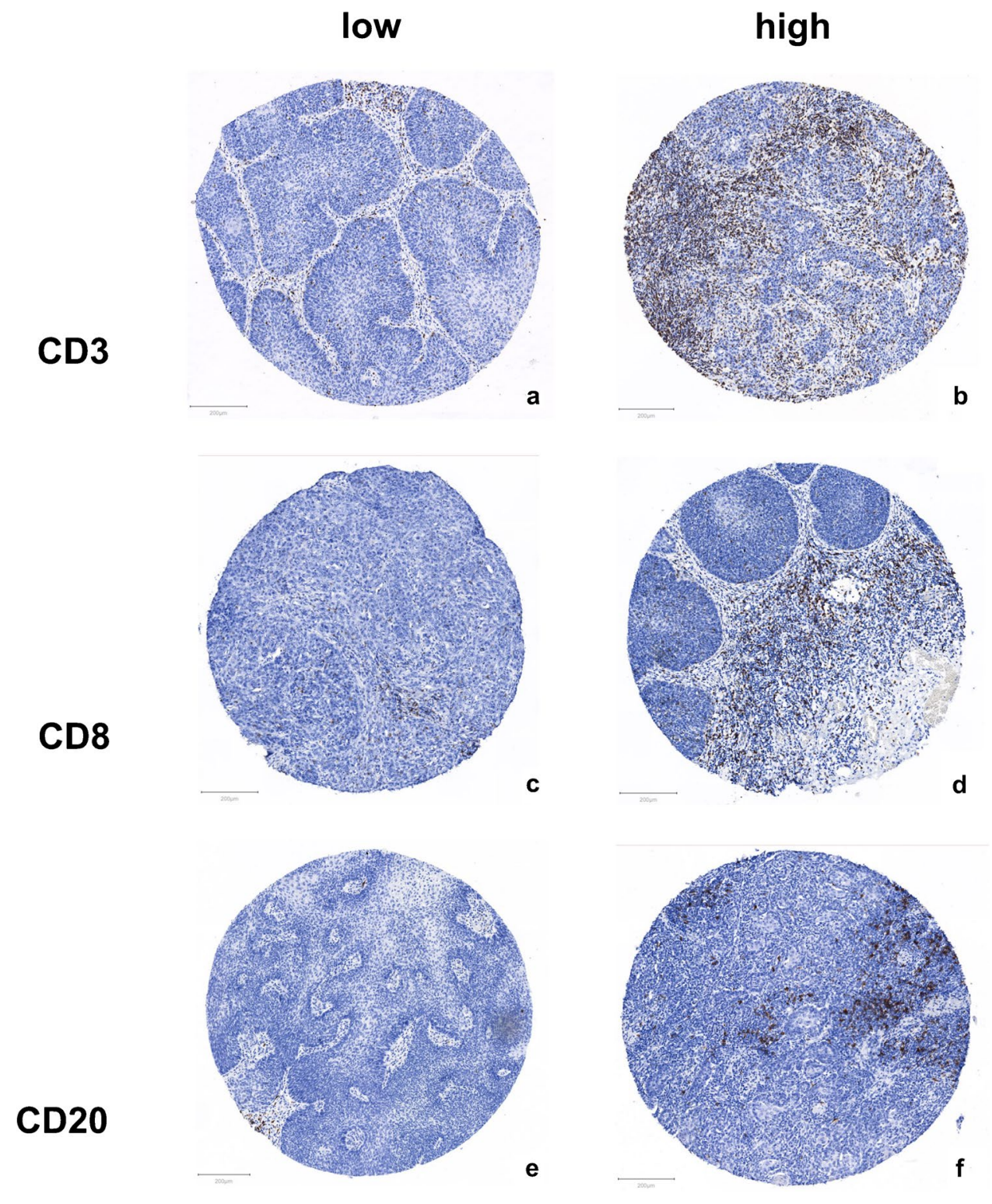

\section{Discussion}

The tumor microenvironment of penile squamous cell carcinomas is complex. Attempts to characterize the immune cells have been undertaken in different retrospective cohorts $[11,12,24]$.

It is known that the penis is a location of immune response as it is the entry for sexually transmitted diseases [25]. In the setting of carcinomas, an immunologic role of the cancer cells had been postulated. Therefore, studies were undertaken investigating the cancer 'immune profile' based on antibodies to characterize subsets of immune cells that accumulate peri- and intratumoral [26]. Especially for CD3 and CD8, studies described differences in the risk of death or progression in some tumors [26]. It is also known that, additionally to T-cells, memory B-cells, as a driver of adaptive immunity for humoral response, are residing in the penis [25]. The interaction between B- and T-cells is a substantial part of immunity. Therefore, in recent years, studies were initiated to investigate B-cells as part of the tumor microenvironment $[27,28]$. That is why we chose to investigate the tumor-associated immune cell infiltrate by means of the antibodies against CD3, CD8 and CD20.

The ICID of squamous cell carcinomas of the penis was investigated via image analysis software based on TMAs. An advantage of this study is the computer-based image analysis software, creating an unbiased view on the tumors. Moreover, TMA replicates were included representing neoplastic, CIS and non-neoplastic ROI of different tumor regions allowing for tumor heterogeneity assessment. By examining the density of the different immune cells rather than their absolute numbers, 
Table 2 Correlations of immune cell infiltrate density in neoplastic tissue with clinicopathological characteristics in invasive penile carcinomas $(n=55)$

\begin{tabular}{|c|c|c|c|c|c|c|c|}
\hline $\begin{array}{l}\text { Clinicopathologi- } \\
\text { cal characteristics } \\
\text { of invasive penile } \\
\text { carcinomas }\end{array}$ & Categorization & $\begin{array}{l}\text { Correlation with } \\
\text { CD3 density in } \\
\text { neoplastic tissue }\end{array}$ & $p$ value & $\begin{array}{l}\text { Correlation with } \\
\text { CD8 density in } \\
\text { neoplastic tissue }\end{array}$ & $p$ value & $\begin{array}{l}\text { Correlation with } \\
\text { CD20 density in } \\
\text { neoplastic tissue }\end{array}$ & $p$ value \\
\hline $\begin{array}{l}\text { Age (range } 41-85 \\
\text { years) }\end{array}$ & $\begin{array}{l}<65 \text { years } \\
\geq 65 \text { years }\end{array}$ & 0.09 & NS & 0.15 & NS & 0.03 & NS \\
\hline Tumor stage & $\begin{array}{l}\text { pT1a } \\
\text { pT1b } \\
\text { pT2 } \\
\text { pT3 } \\
\text { pT4 } \\
\text { pTX }\end{array}$ & -0.31 & $0.03 *$ & -0.18 & NS & -0.10 & NS \\
\hline Nodal status & $\begin{array}{l}\mathrm{pN} 0 \\
\mathrm{pN}>0 \\
\mathrm{pNX}\end{array}$ & -0.30 & NS & -0.04 & NS & -0.35 & NS \\
\hline Grading & $\begin{array}{l}\text { G1 } \\
\text { G2 } \\
\text { G3 }\end{array}$ & $0.05^{\mathrm{a}}$ & NS & $0.19^{\mathrm{a}}$ & NS & $0.00^{\mathrm{a}}$ & NS \\
\hline $\mathrm{L}$ & $\begin{array}{l}\text { L0 } \\
\text { L1 }\end{array}$ & -0.02 & NS & -0.02 & NS & -0.10 & NS \\
\hline V & $\begin{array}{l}\text { V0 } \\
\text { V1 }\end{array}$ & -0.02 & NS & 0.10 & NS & 0.02 & NS \\
\hline Pn & $\begin{array}{l}\text { Pn0 } \\
\text { Pn1 }\end{array}$ & 0.03 & NS & -0.01 & NS & -0.12 & NS \\
\hline $\mathrm{R}$ & $\begin{array}{l}\mathrm{R} 0 \\
\mathrm{R}>0 \\
\mathrm{RX}\end{array}$ & -0.06 & NS & -0.16 & NS & 0.20 & NS \\
\hline Infiltration pattern & $\begin{array}{l}\text { Infiltrative pattern } \\
\text { Pushing margin }\end{array}$ & -0.13 & NS & -0.10 & NS & -0.13 & NS \\
\hline $\begin{array}{l}\text { Morphological tumor } \\
\text { type }\end{array}$ & $\begin{array}{l}\text { Usual } \\
\text { Basaloid }\end{array}$ & 0.15 & NS & $\mathbf{0 . 3 3}$ & $0.02 *$ & 0.13 & NS \\
\hline $\begin{array}{l}\text { HPV status (LCD } \\
\text { array) }\end{array}$ & $\begin{array}{l}\text { Negative or low risk } \\
\text { High risk } \\
\text { Unknown }\end{array}$ & 0.01 & NS & 0.11 & NS & 0.24 & NS \\
\hline $\begin{array}{l}\text { Immunohistochem- } \\
\text { istry (IHC) }\end{array}$ & & & & & & & \\
\hline p16 IHC & $\begin{array}{l}\text { Negative } \\
\text { Positive }\end{array}$ & 0.03 & NS & 0.13 & NS & 0.25 & NS \\
\hline
\end{tabular}

Tumor stage: Nomenclature according to current WHO classification system, Nodal stage-pN0: No tumor infiltrated lymph nodes detected in pathological examination, $\mathrm{pN}>0$ : Tumor infiltrated lymph nodes detected in pathological examination, pNX: Pathological lymphonodal status unknown, L: Lymphovascular invasion—L0: No lymphovascular invasion, L1: Lymphovascular invasion, V: Vascular invasion-V0: No vascular invasion, V1: Vascular invasion, Pn: Perineural invasion-Pn0: No perineural invasion, Pn1: Perineural invasion; R: Residual tumor-R0: No residual tumor, R > 0: Residual invasive tumor or residual carcinoma in situ, RX: Unknown status. HPV: Human papillomavirus

NS non-significant $p$ value

*Significant $p$ value

${ }^{a}$ Correlation calculated using Kendall's correlation as an equivalent to Jonckheere-Terpstra test 

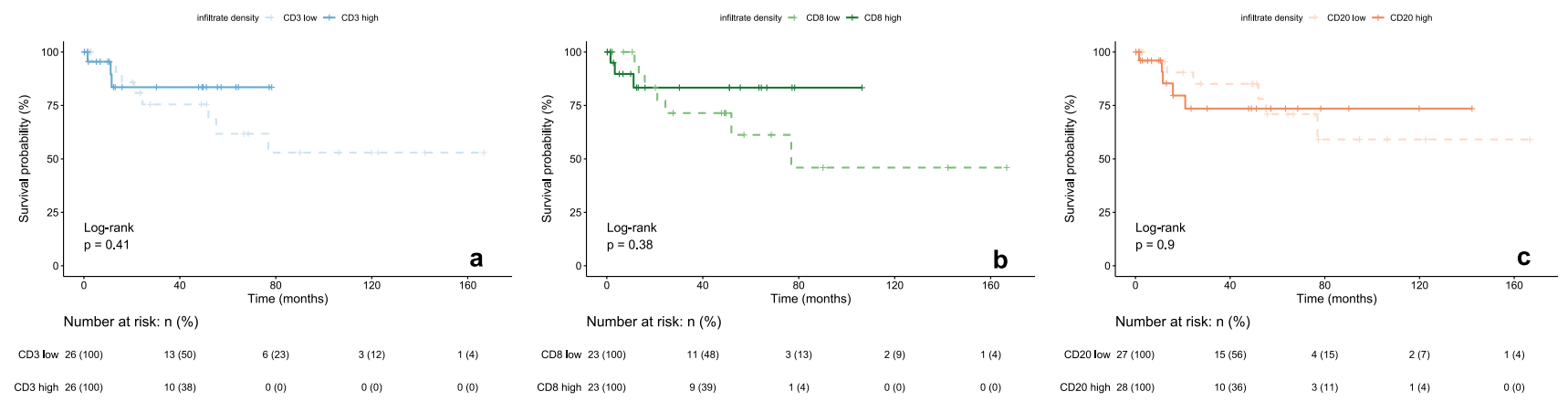

Fig. 4 Kaplan-Meier plots showing the results of the survival analysis for groups of high vs low immune cell infiltrate density in neoplastic tissue for CD3-positive cells (a), CD8-positive cells (b) and CD20-

comprehensive and comparable data for characterizing the (immune) tumor microenvironment in penile carcinomas were retrieved.

There was a statistically significant association between neoplastic tissue and increased ICID stained with antibodies against CD3, CD8 and CD20. It is well known that tumors induce an immunologic response with consecutive interaction by the host [26]. Especially in HPV-associated cancers, such as penile squamous cell carcinomas, the amount of tumor-associated immune cells is increased [10]. Studies indicate a survival benefit for patients with increased amount of immune cells in association with the tumor [26]. This fact is used for anti-cancer immune therapies targeting specific immune cells. A popular example is the PD-L1 antibody which generates positive effects on patients' OS in a growing amount of tumor entities. It is known that PD-L1 is expressed in penile carcinomas [17].

In this study, the ICID of invasive squamous cell carcinomas of the penis was investigated with antibodies against CD3, CD8 and CD20.

CD20 is a marker that can be proven on B-cells prior to their differentiation to plasma cells. It is expressed on naïve and memory $\mathrm{B}$-cells. Most of the studies investigating B-cells in human cancer found a positive prognostic effect for CD20-positive B-cells in cancer types [29]. In one study investigating penile squamous cell carcinomas, the effect was described as neutral [11]. There might be a bias caused by the small number of penile carcinomas investigated compared to the large number of patients in the breast cancer cohort. Indirectly the effect of B-cells is already under investigation in penile squamous cell carcinomas through blocking of inhibitory signals in the PD-1/PD-L1 pathway in studies [24]. This pathway is important for interactions between plasma cells and $\mathrm{T}$ follicular helper cells [30]. Expecting CD20-positive B-cells to differentiate towards plasma cells, future studies may utilize double staining for a CD20 and a plasma cell marker to elucidate the amount and prognostic impact of plasma cells in invasive penile squamous cell positive cells (c). There was no statistically significant difference in survival between groups of high vs low CD3, CD8 and CD20-positive ICID in our cohort of penile neoplasias

carcinomas of the penis to further provide evidence for antiPD-L1 therapies.

CD3 is expressed on T-cells. Some CD3-positive T-cells also express CD8. Non-anergic CD8-positive cells are cytotoxic T-cells with the capability of killing tumor cells [26]. In a meta-analysis, CD3 and CD8-positive cells had a positive effect on prognosis in different studies, also dependent on the study size [26]. In this study, a significant effect on overall survival regarding CD3-positive cells was not shown but might be readable from the risk tables, which is difficult to determine with the sample size of this cohort. This would be in line with a recent study by our group, which showed that the amount of immune cells, semi-quantitatively estimated, is associated with tumor stage and therefore indirectly with survival [17].

In recent years, attention was drawn to ratios between subsets of immune cells as predictive values. This approach enhances the view towards the immune system as a team player. There are conflicting data towards the predictive value on the ratio of CD3 and CD8-positive cells in different cancer types [26]. Therefore, further studies are needed applying more antibodies to understand the complex interactions and dynamics of the immune response and their possible targets for specific therapies.

Other studies reported different effects of survival depending on the localization of the immune cells (intratumoral and stromal) in specific tumor entities [31]. Possibly, unraveling those compartments would reveal statistically significant $p$ values in our cohort. Nevertheless, it is not feasible in routine use and was therefore neither attempted nor intended.

In our cohort, the density of CD8-positive T-cells was associated with basaloid tumor cell morphology. That is not surprising since basaloid morphology is related to HPV infection and therefore to an increased amount of immune cells [10]. However, a significant correlation between HPV status and density of CD8-positive cells was not shown, which is most likely due to the sample size. A 
significant correlation should be present in a larger cohort, which further illustrates the need for additional studies.

Other parameters such as age group or lymphonodal status showed no association with the measured ICID. Interestingly, we were not able to show an association between overall survival and CD8-positive T-cells in our cohort, as did others [32]. This might also relate to sample size.

Sample size was a limiting factor for obtaining statistically significant correlations in this study, which is a frequent challenge in studies on penile cancer due to the small number of cases throughout Europe. Stronger correlations should be expected in studies with even larger sample sizes, especially for survival analyses and correlations of immune cell infiltrate densities with clinical data such as grading and staging categories.

Nevertheless, this cohort, with regard to the selection of methods and the resulting low bias and consideration for tumor heterogeneity, still allows a comprehensive review of the immune tumor microenvironment in penile cancer.

Future studies are needed to further describe and understand the tumor-associated immune cell infiltrate in penile squamous cell carcinomas and to find new targets for antitumor therapy regimens in this mutilating disease.

\section{Conclusion}

Neoplastic tissue in penile squamous cell carcinomas is associated with an increased density of immune cells as shown with antibodies against CD3, CD8 and CD20. Therefore, it was shown, that not only T-cells are increased in number and are possible targets to potential anti-tumor therapies, but also CD20-positive B-cells. This enhances the need to further elucidate the role of B-cells in penile squamous cell carcinomas to eventually generate possible new target strategies for this neoplasm.

Further studies are needed to generate insight on the activation status of the immune cells. Maybe in that way new strategies can be elucidated facilitating this microenvironment in order to generate an increased anti-tumor effect of the immune cell infiltrate.

Acknowledgements The authors greatly acknowledge technical assistance by Nina Becker.

Author contribution All authors whose names appear on the submission (LH, KB, JvG, NF, MD, SV, PJW, RW)

1) made substantial contributions to the conception or design of the work; or the acquisition, analysis, or interpretation of data; or the creation of new software used in the work;

2) drafted the work or revised it critically for important intellectual content;

3) approved the version to be published; and
4) agree to be accountable for all aspects of the work in ensuring that questions related to the accuracy or integrity of any part of the work are appropriately investigated and resolved.

Funding Open Access funding enabled and organized by Projekt DEAL.

\section{Declarations}

Ethics approval Material and pseudonymized patient data used in this study were provided by the University Cancer Center Frankfurt (UCT). Written informed consent was obtained from all patients, and the study was approved by the institutional review board of the UCT and the ethical committee at the University Hospital Frankfurt, according to the Declaration of Helsinki (project-numbers: SUG-02-2017, SUG6-2018).

Conflict of interest PJW has received consulting fees and honoraria for lectures by Bayer, Janssen-Cilag, Novartis, Roche, MSD, Astellas Pharma, Bristol-Myers Squibb, Thermo Fisher Scientific, Molecular Health, Hedera Dx, Sophia Genetics, Qiagen and Astra Zeneca. All other authors have declared that no conflict of interest exists.

Open Access This article is licensed under a Creative Commons Attribution 4.0 International License, which permits use, sharing, adaptation, distribution and reproduction in any medium or format, as long as you give appropriate credit to the original author(s) and the source, provide a link to the Creative Commons licence, and indicate if changes were made. The images or other third party material in this article are included in the article's Creative Commons licence, unless indicated otherwise in a credit line to the material. If material is not included in the article's Creative Commons licence and your intended use is not permitted by statutory regulation or exceeds the permitted use, you will need to obtain permission directly from the copyright holder. To view a copy of this licence, visit http://creativecommons.org/licenses/by/4.0/.

\section{References}

1. Hakenberg OW, Dräger DL, Erbersdobler A, Naumann CM, Jünemann KP, Protzel C (2018) übersichtsarbeit: Diagnostik und therapie des Peniskarzinoms. Deutsches Arzteblatt International. Deutscher Arzte-Verlag GmbH, pp 646-652. https://doi.org/10. 3238/arztebl.2018.0646

2. Moch H, Cubilla AL, Humphrey PA, Reuter VE, Ulbright TM. The 2016 WHO classification of tumours of the urinary system and male genital organs-part A: renal, penile, and testicular tumours. Eur Urol [Internet]. Elsevier B.V.; 2016 [cited 2021 Mar 24]; 70: 93-105. doi: https://doi.org/10.1016/j.eururo.2016. 02.029 .

3. Iorga L, Marcu R, Diaconu C, Stanescu A, Stoian A, Mischianu D, Surcel M, Bungau S, Constantin T, Boda D, Fekete L, Bratu O. Penile carcinoma and HPV infection (Review). Exp Ther Med [Internet]. Spandidos Publications; 2019 [cited 2021 Apr 22]; 20: 91-6. doi: 10.3892/etm.2019.8181.

4. Chahoud J, Kohli M, Spiess PE. Management of advanced penile cancer. Mayo Clin Proc [Internet]. Elsevier; 2021 [cited 2021 Aug 13]; 96: 720-32. doi: 10.1016/J.MAYOCP.2020.06.031.

5. Pandey D, Mahajan V, Kannan RR (2006) Prognostic factors in node-positive carcinoma of the penis. J Surg Oncol. 93:133-138. https://doi.org/10.1002/JSO.20414 
6. Kroemer G, Senovilla L, Galluzzi L, André F, Zitvogel L. Natural and therapy-induced immunosurveillance in breast cancer. Nat Med 20152110 [Internet]. Nature Publishing Group; 2015 [cited 2021 Aug 5]; 21: 1128-38. doi: 10.1038/nm.3944.

7. Balermpas P, Rödel F, Weiss C, Rödel C, Fokas E. Tumor-infiltrating lymphocytes favor the response to chemoradiotherapy of head and neck cancer. Oncoimmunology [Internet]. Taylor \& Francis; 2014 [cited 2021 Oct 12]; 3. doi: 10.4161/ONCI.27403.

8. Balermpas P, Martin D, Wieland U, Rave-Fränk M, Strebhardt K, Rödel C, Fokas E, Rödel F. Human papilloma virus load and PD-1/PD-L1, CD8 + and FOXP3 in anal cancer patients treated with chemoradiotherapy: rationale for immunotherapy human papilloma virus load and PD-1/PD-L1, CD8 C and FOXP3 in anal cancer patients treated with chemoradiotherapy: Rationale for immunotherapy. 2017 [cited 2021 Oct 12]; . doi: 10.1080/2162402X.2017.1288331.

9. Litwin TR, Irvin SR, Chornock RL, Sahasrabuddhe V V., Stanley $\mathrm{M}$, Wentzensen N. Infiltrating T-cell markers in cervical carcinogenesis: a systematic review and meta-analysis. Br J Cancer 2020 1244 [Internet]. Nature Publishing Group; 2020 [cited 2021 Oct 12]; 124: 831-41. doi: 10.1038/s41416-020-01184-x.

10. Lohneis P, Boral S, Kaufmann AM, Lehmann A, Schewe C, Dietel M, Anagnostopoulos I, Jöhrens K. Human papilloma virus status of penile squamous cell carcinoma is associated with differences in tumour-infiltrating T lymphocytes. Virchows Arch 20144663 [Internet]. Springer; 2014 [cited 2021 Aug 19]; 466: 323-31. doi: 10.1007/S00428-014-1713-4.

11. Vassallo J, Rodrigues AFF, Campos AHJFMFM, Rocha RM, da Cunha IW, Zequi SC, Guimarães GC, da Fonseca FP, Lopes A, Cubilla A, Soares FA. Pathologic and imunohistochemical characterization of tumoral inflammatory cell infiltrate in invasive penile squamous cell carcinomas: Fox-P3 expression is an independent predictor of recurrence. Tumor Biol 2015364 [Internet]. Springer; 2015 [cited 2020 Dec 4]; 36: 2509-16. doi: 10.1007/ S13277-014-2864-2.

12. Ottenhof SR, Djajadiningrat RS, Thygesen HH, Jakobs PJ, Józwiak K, Heeren AM, de Jong J, Sanders J, Horenblas S, Jordanova ES. The prognostic value of immune factors in the tumor microenvironment of penile squamous cell carcinoma. Front Immunol [Internet]. Frontiers Media S.A.; 2018 [cited 2020 Dec 2]; 9: 11. doi: 10.3389/fimmu.2018.01253.

13. Ahmed ME, Falasiri S, Hajiran A, Chahoud J, Spiess PE. The immune microenvironment in penile cancer and rationale for immunotherapy. 2020 [cited 2021 Apr 30]; 9: 3334. Available from /pmc/articles/PMC7603091/

14. Khazaie K, Block MS, Biragyn A, Schenk M, Maibach F, Sadozai $\mathrm{H}$, Morteza S, Jafari S, Hunger RE. Tumor-infiltrating lymphocytes and their prognostic value in cutaneous melanoma. 2020; . doi: 10.3389/fimmu.2020.02105.

15. Meyer S, Fuchs TJ, Bosserhoff AK, Hofstädter F, Pauer A, Roth V, Buhmann JM, Moll I, Anagnostou N, Brandner JM, Ikenberg $\mathrm{K}$, Moch $\mathrm{H}$, Landthaler M, et al. A seven-marker signature and clinical outcome in malignant melanoma: a large-scale tissuemicroarray study with two independent patient cohorts. PLoS One [Internet]. Public Library of Science; 2012 [cited 2021 Oct 4]; 7: e38222. doi: 10.1371/JOURNAL.PONE.0038222.

16. Moch H, Humphrey PA, Ulbright TM, Reuter VE, International Agency for Research on Cancer. WHO classification of tumours of the urinary system and male genital organs [Internet]. [cited 2018 May 3]. 356 p. Available from http://publications.iarc.fr/ Book-And-Report-Series/Who-Iarc-Classification-Of-Tumours/ Who-Classification-Of-Tumours-Of-The-Urinary-System-AndMale-Genital-Organs-2016
17. Müller T, Demes M, Lehn A, Köllermann J, Vallo S, Wild PJ, Winkelmann R. The peri- and intratumoral immune cell infiltrate and PD-L1 status in invasive squamous cell carcinomas of the penis. Clin Transl Oncol [Internet]. Springer Science and Business Media Deutschland GmbH; 2021 [cited 2021 Sep 28]; : 1-11. doi: 10.1007/S12094-021-02694-7/FIGURES/5.

18. Bankhead P, Loughrey MB, Fernández JA, Dombrowski Y, McArt DG, Dunne PD, McQuaid S, Gray RT, Murray LJ, Coleman HG, James JA, Salto-Tellez M, Hamilton PW. QuPath: open source software for digital pathology image analysis. Sci Rep [Internet]. Nature Publishing Group; 2017 [cited 2020 Nov 17]; 7: 1-7. doi: 10.1038/s41598-017-17204-5.

19. Team RDC. A language and environment for statistical computing. R Found Stat Comput [Internet]. 2020 [cited 2020 Aug 29]; 2: https://www.R-project.org. Available from http://www.r-proje ct.org

20. RStudio Team R Core Team, Wickham H, Chang W, Henry L, Pedersen TL, Takahashi K, Wilke C, Woo K, Yutani H, Dunnington D, Revelle W, Therneau TM. ggplot2: create elegant data visualisations using the grammar of graphics [Internet]. Vienna, Austria; 2021. Available from https://github.com/therneau/survi val

21. Wickham H. ggplot2: elegant graphics for data analysis [Internet]. Springer-Verlag New York; 2016. Available from https://ggplot2. tidyverse.org

22. Revelle W. psych: procedures for psychological, psychometric, and personality research [Internet]. 2021. Available from https:// personality-project.org/r/psych/

23. Therneau TM. survival: survival analysis [Internet]. 2021. Available from https://github.com/therneau/survival

24. De Vries H-M, Ottenhof SR, Horenblas S, Van Der Heijden MS, Jordanova ES. Defining the tumor microenvironment of penile cancer by means of the cancer immunogram. 2019 [cited 2020 Dec 2]; . doi: 10.1016/j.euf.2019.02.019.

25. Sennepin A, Real F, Duvivier M, Ganor Y, Henry S, Damotte D, Revol M, Cristofari S, Bomsel M (2017) The human penis is a genuine immunological effector site. Front Immunol. Frontiers Media S.A. 8:1732. https://doi.org/10.3389/FIMMU.2017.01732/ BIBTEX

26. Gooden MJM, De Bock GH, Leffers N, Daemen T, Nijman HW. The prognostic influence of tumour-infiltrating lymphocytes in cancer: a systematic review with meta-analysis [Internet]. British Journal of Cancer. Nature Publishing Group; 2011 [cited 2020 Dec 17]. p. 93-103. doi: 10.1038/bjc.2011.189.

27. Tsou P, Katayama H, Ostrin EJ, Hanash SM. The emerging role of B cells in tumor immunity. cancer res [Internet]. American Association for Cancer Research; 2016 [cited 2021 Nov 23]; 76: 5597-601. doi: 10.1158/0008-5472.CAN-16-0431.

28. Nielsen JS, Sahota RA, Milne K, Kost SE, Nesslinger NJ, Watson $\mathrm{PH}$, Nelson BH. CD20+ tumor-infiltrating lymphocytes have an atypical CD27- memory phenotype and together with CD8+ T cells promote favorable prognosis in ovarian cancer. Clin Cancer Res [Internet]. American Association for Cancer Research; 2012 [cited 2021 Nov 23]; 18: 3281-92. doi: 10.1158/1078-0432. CCR-12-0234.

29. Wouters MCA, Nelson BH. Prognostic significance of tumorinfiltrating B cells and plasma cells in human cancer. Clin Cancer Res [Internet]. American Association for Cancer Research; 2018 [cited 2021 Aug 23]; 24: 6125-35. doi: 10.1158/1078-0432. CCR-18-1481.

30. Good-Jacobson KL, Szumilas CG, Chen L, Sharpe AH, Tomayko MM, Shlomchik MJ. PD-1 regulates germinal center B cell survival and the formation and affinity of long-lived plasma cells. 
Nat Immunol 2010116 [Internet]. Nature Publishing Group; 2010 [cited 2021 Aug 24]; 11: 535-42. doi: 10.1038/ni.1877.

31. Rathore AS, Kumar S, Konwar R, Makker A, Negi MPS, Goel MM. CD3+, CD4+ \& CD8+ tumour infiltrating lymphocytes (TILs) are predictors of favourable survival outcome in infiltrating ductal carcinoma of breast. Indian J Med Res [Internet]. Wolters Kluwer -- Medknow Publications; 2014 [cited 2021 Sep 30]; 140: 361. Available from /pmc/articles/PMC4248382/
32. Deng C, Li Z, Guo S, Chen P, Chen X, Zhou Q, Chen J, Yu X, Wu X, Ma W, Xie Q, Ye Y, Li Y, et al. Tumor PD-L1 expression is correlated with increased TILs and poor prognosis in penile squamous cell carcinoma. 2017 [cited 2019 Aug 4]; . doi: $10.1080 / 2162402 X .2016 .1269047$.

Publisher's note Springer Nature remains neutral with regard to jurisdictional claims in published maps and institutional affiliations. 